\title{
Perceptions of contraceptives as factors in birth outcomes and menstruation patterns in a rural community in Siaya county, Western
}

\section{Kenya}

\author{
George O Onyango ${ }^{1}$, George Ayodo ${ }^{2}$, Nadia Smith- Diamond ${ }^{3}$, Salome Wawire ${ }^{4}$ \\ 1 Jaramogi Oginga Odinga University of Science and Technology, Bondo, Kenya, ${ }^{2}$ Health Sciences, Jaramogi Oginga Odinga University of Science and \\ Technology, Bondo, Kenya, ${ }^{3}$ University of California, San Francisco, California, USA, ${ }^{4}$ Independent Researcher \\ Keywords: kenya, preterm, menstruation, contraceptive
}

https://doi.org/10.29392/001c.13690

Journal of Global Health Reports

Vol. 4, 2020

\begin{abstract}
Unmet need for contraception persists in Kenya despite an increase in awareness and availability of family planning services. There is a dearth of information on experiences and perceptions of contraception, specifically related to birth outcomes and menstruation patterns, in western Kenya. The aim of this study was to explore knowledge and perceptions on contraception, menstruation, and birth outcomes. In-depth interviews were conducted with 45 respondents; adolescent girls with children, mothers over age 20, and fathers. Six Focus Group Discussions were held with 60 participants drawn from Skilled Birth Attendants, Traditional Birth Attendants, and Community Leaders. A thematic content analysis approach was used. We found that most participants knew about contraceptives and accessed the services in their local health facilities. A majority of the women associated problems with the inability to track menstruation with contraceptive side effects. Beliefs linking contraceptives to the occurrence of preterm and birth defects were also reported among the respondents. Overall, most women approved of contraceptives, however, perceptions remained largely negative among men. While contraception remains an important health service for improvement of maternal-child health, the belief that it affects menstruation and contributes to preterm births hinders its uptake in the community. There should be programmatic intervention targeting families to change the negative perceptions linked to contraceptive use.
\end{abstract}

Contraceptive use is important in helping people achieve desired fertility, avoid unintended pregnancies, and prevent sexually transmitted infections, therefore directly influencing maternal and child health. ${ }^{1}$ At least 214 million women in developing countries are facing the unmet need for contraceptives despite many global initiatives including Family Planning 2020 and the Sustainable Development Goals (2016-2030). ${ }^{2}$ Additionally, due to the high unmet need for contraceptives, Sub Saharan Africa (SSA) has the highest burden of unintended pregnancies, unsafe abortions, and maternal mortality. ${ }^{3}$ Several factors have been linked to the low contraceptive uptake among women in developing countries. Knowledge, beliefs, perceived side effects, spousal support, cultural practices, and poor health infrastructure in rural communities are some of the documented hindrances to access and utilization of contraceptive services. ${ }^{4}$

Global and national policies have emphasized strategies for improving contraceptive access to an additional 120 million women by $2020 .{ }^{4}$ Recent research in Uganda has shown that comprehensive knowledge and understanding of contraceptives is associated with increased uptake and effective use. ${ }^{5}$ According to the Kenya Demographic Health Survey (2015), the unmet need for contraception among women declined from $26 \%$ in 2010 to the current $18 \%$ but varies sig- nificantly according to regions, levels of education, and economic status. ${ }^{6}$ Increased uptake of contraceptives has been associated with better living standards, gender equity and greater benefits to the individual, family, and nation. ${ }^{3}$ Family planning programs have been prioritized in many countries as some of the most cost-effective development investments due to their direct impact on improving lives through national security and enhanced economic benefits to communities. ${ }^{7}$ Therefore, there are several compelling reasons for developing countries to prioritize contraceptives as a strategy for attaining sustainable socio-economic growth. Despite remarkable levels of awareness on the benefits associated with contraceptives use, it is unclear why the uptake remains low in most of the SSA.

While a lot of global effort and focus have been directed at addressing the unmet need for contraception especially in the developing world, the phenomenon persists especially in poor rural settings. ${ }^{8}$ SSA continues to have the lowest contraceptive prevalence at $24 \%$ and the highest unmet need for contraceptives at $25 \% .{ }^{9}$ A study in Nigeria established that levels of awareness on contraceptives were nearly $100 \%$ in most places including rural areas, yet unintended pregnancies and sexually transmitted infections were still prevalent. ${ }^{1}$ Similarly, contraceptive awareness in Kenya is relatively high, yet significant unmet need for contracep- 
tives persists in most rural areas. ${ }^{6}$ It is therefore important to explore the knowledge and experiences of women to understand the underlying and confounding factors behind this phenomenon. There is a dearth of information on experiences and perceptions of contraception, specifically related to birth outcomes and menstruation patterns, in western Kenya.

Studies have established varied preferences among men and women concerning the use of contraceptives in regulating fertility. ${ }^{5}$ Perceived or actual partner's fertility preferences and attitudes significantly influence the choices of women on contraceptive use. ${ }^{4}$ Though some studies have emphasized the involvement of men in the programs that address the unmet need for contraceptives, culturally motivated spousal hindrance to the uptake has been documented in many areas. ${ }^{9}$ It is noteworthy that cultural norms in rural communities vary significantly from peri-urban and urban areas where the gender roles have changed. According to research conducted in several developing countries, a significant proportion of married women do not access and use contraceptives due to spousal opposition. ${ }^{10}$ Additionally, contraceptives have been linked to adverse health effects such as infertility, irregular menstruation, stillbirths, and preterm births. ${ }^{4}$ The purpose of this study was therefore to explore knowledge and perceptions of men, women, and health workers on contraception, menstruation, and birth outcomes (including preterm birth).

\section{METHODS}

This qualitative study was carried out between August and November 2017 in a rural community living along the shores of Lake Victoria in Siaya County, Western Kenya. The study population was selected from households surrounding three health facilities namely; Uyawi, Usigu, and Got Agulu health centers in Bondo Sub County. The study participants were recruited from the community through the leaders, community health volunteers, and the health workers attached to the health facilities. The interviews were scheduled by the research assistants and conducted in the health facilities at appointed times that were convenient to the participants. The interviews were conducted in the local language (Dholuo), audio-recorded, and transcribed. The transcripts were then translated into English. Each of the In-Depth Interviews (IDIs) took about one and a half hours while the Focus Group Discussions (FGDs) took about three hours each. Before the data collection, the interviewees were fully informed on the nature and purpose of the study. They were also informed of any possible risks, their voluntary participation, and assured of the confidentiality of the information collected. They then signed the forms for consent before each of the interviews commenced. The study met all the ethical review approval requirements from the Ethical Review Board at Jaramogi Oginga Odinga Teaching and Referral Hospital (JOOTRH) before commencement.

The data used in this article were part of a larger study project that focused on preterm birth sponsored by Melinda and Gates Foundation in East Africa. Data collection was preceded by a piloting phase under which the instruments of data collection were tested for participant understanding. The piloting was conducted in a neighboring Gobei
Health Centre, also in Bondo Sub-county after which the data collection tools were reviewed.

The target group selected included adolescent girls, men, and women in childbearing age who had experience with preterm births. In-depth interviews were conducted with 45 participants evenly drawn from adolescent mothers, adult mothers, and fathers, all who had children under 5 years. Additionally, 6 FGDs were held with a total of 60 participants with skilled birth attendants (SBA), traditional birth attendants (TBAs) and Community Leaders, in groups of about 10 . The IDIs and FGDs were conducted by research assistants under the guidance of the investigators. The data was collected through note-taking, audio-recording, and photography. The use of both the IDIs and FGDs provided a process in which the data collected was verified and triangulated through varied sources. The data collected were transcribed and translated into English before being read and cleaned. Content and thematic analysis was conducted and a codebook was developed. The data were analyzed using Atlas-ti Version 7.5.7 Software.

\section{RESULTS}

\section{DEMOGRAPHIC CHARACTERISTICS OF PARTICIPANTS}

Table 1 summarizes the socio-demographic characteristics of the study participants. Adult women were on average about 24 years, men about 35 years, and adolescent women about 18 years old. Most women had primary education (60\%), whereas men were more highly educated. All respondents were Christian. Adult women had on average about 2 children, adolescent women 1 child and men 3 children. While fishing was the economic mainstay of the community, a majority of women in the study were involved in small scale businesses and subsistence farming for livelihood. A minority of the residents were in gainful formal employment while levels of poverty in the area were relatively high. Most of the residents in the area belonged to the Luo ethnic community with a mix of others from different ethnicities.

\section{KNOWLEDGE ON CONTRACEPTIVES: DIFFERENCES BY AGE}

All the participants in the study had knowledge of at least one contraceptive method and had either used a method in the past or were currently using a method. Most of the participants in the study indicated that they were using methods such as implants, injections or Intra-Uterine Devices (IUD) but a few were on rhythm method, condoms, and traditional methods. Married men and women knew more about contraceptives than those who were yet to get married. An interview with a young newly married father revealed a lack of sufficient information on contraceptives and unmet needs, leading to unintended pregnancy.

Respondent: What we didn't do that we were supposed to do by that time, we were supposed to go the hospital for advice or we could have been advised on how to prevent unexpected pregnancy.

Interviewer: That your baby is the first baby?

Respondent: Yes.

Interviewer: Then why do you say it was unexpected? Were you both married at that time? 
Table 1. Participants' demographic summary

\begin{tabular}{|l|l|l|c|}
\hline Parameter & Adult Mothers $(n=15)$ & Adolescent Mothers $(n=15)$ & Men $(n=15)$ \\
\hline Age (mean, SD) & $24.8, \pm 3.2$ & $17.9, \pm 1.0$ & $35.2, \pm 9.4$ \\
\hline Education & & & \\
\hline Primary & $60 \%(n=9)$ & $60 \%(n=9)$ & $46.7 \%(n=7)$ \\
\hline Secondary & $26.7 \%(n=4)$ & $40 \%(n=6)$ & $46.7 \%(n=7)$ \\
\hline Tertiary & $13.3 \%(n=2)$ & 0 & $6.7 \%(n=1)$ \\
\hline Number of children (mean, SD) & $2.1, \pm 0.6$ & $1.3, \pm 0.6$ & $3.3, \pm 1.8$ \\
\hline
\end{tabular}

Respondent: By that time we were a girlfriend, boyfriend, we were just friends.

Interviewer: You were not yet married?

Respondent: No we had not yet been married (25year old father of one).

While most of the younger respondents approved of contraceptives, the older generation was less supportive of contraceptive use. According to a TBA in an FGD, contraceptives were negatively viewed by the older generation in the community.

On the issue of family planning, in the past a person could have as many children as she could. Nowadays we have been taught about spacing. Some do not accept to be told about family planning. For some if you tried to tell them you may be offended because some people do not accept this issue of family planning, especially the elderly. I could say some old men and women do not want this issue of family planning. If they hear the daughter-in-law has gone for family planning she can be sent away (woman, 62 years, TBA)

In contrast to the views of the elderly on contraceptives, the younger generation was more supportive of the use of contraceptives, especially for spacing of births. According one father interviewed, family planning was important in enabling families to space children appropriately and avoid undue economic burden;

Sometimes it depends on when a child is still very young, has not completed even two years and may be you planned that the child should be at least three years when he/she is even in pre-unit before you get another baby. So when you follow a child very closely, you may realize that even school fees may be a problem for them (35 year old father of three).

\section{PERCEPTIONS OF IMPACT OF CONTRACEPTIVES ON MENSTRUATION}

A majority of the women associated the contraceptives they were using or contraceptives in general with irregular menstruation. Some felt that contraceptives affected the patterns of their menstruation, making it difficult to track their monthly periods and leading to their inability to plan pregnancies or to avoid unintended pregnancies;

Respondent: I used to track before I started using family planning but since I started it keeps on changing. Interviewer: So you think that family planning is the main factor?

Respondent: Yes, it is, some people even stay for 3 or 5 months without getting the menses, some even years. Interviewer: Which family plan do you use?

Respondent: I used to use the injection that lasts 3 months, currently am using the one for 3 years (23year old, married, mother of three).

Further, some of the respondents believed that using contraceptives either stopped their menses all together or contributed to abnormally heavy flow.
Respondent: My menstrual cycle has always been irreg- ular, I do not have a specific date of the month when they come, and they always get me off guard. This month they can come on $30^{\text {th }}$, the next month on $1^{\text {st }}$, the following month on $27^{\text {th }}$ so I don't have a specific date when I can say that I will get my menses.
Interviewer: Since you started using family planning, do you have your menstrual cycle?
Respondent: No I don't see my periods at all Interviewer: At all at all
Respondent: At all (21 year old, married, mother of two).

An interview with a male respondent demonstrated the common perception on the impact of some family planning methods on menstrual flow among some women.

Respondent: One would say that his wife has taken two months before experiencing menstrual periods. So he would ask that: why is that happening? There are also some family planning methods which when are used some people don't experience menses, some also experience over bleeding, so that can also happen.

Interviewer: What reason are they giving for one who is using family planning and is either not experiencing menses or is experiencing excessive bleeding?

Respondent: Some don't experience their menses at all (31 years, married, father of two).

In an FGD interview, one of the discussants (a TBA) narrated her encounter with a girl who she believed had a heavy flow because of the use of contraceptives.

Respondent: There is a certain girl who goes to school, she is in form 2. Her mother told me that she had been on family planning and whenever she was on her period she bled so heavily that she could not even go to school. So her mother stopped her from family planning. So I advised her to take care of herself because she was not able to use the medicine. She should take care of 
herself because that is when she could go to school. She should abstain from men because if she does not do that she could get pregnant. Her education could stop at that point and that would not be a good thing. Girls should be able to continue with their education (55 years, Woman, TBA)

\section{HUSBAND OPPOSITION AS A BARRIER}

While most women viewed contraceptives positively despite the perceived effects on menstruation patterns, a majority of men were averse to their use. Therefore, some of the women secretly used contraceptives without involving their spouses. However, the reliance on covert use did create barriers for women, as one female respondent explained how she got pregnant after failing to get financial support from the spouse to access family planning services in time.

Respondent: I could say it was unintended because by then I was on the 3-month family planning method. I was supposed to go for the next dose and I do not even know what happened. I did not go back because I had sneaked there the first time I went.

Interviewer: Sneaked?

Respondent: My husband was against the idea of family planning. When it was time to go back and I needed to ask him for money I could not. Our home is far from Nango [location of health facility] I told myself I would wait until I get money on my own and then I would go for family planning. Two weeks later I began feeling ill for about two months. I came to hospital and discovered I was pregnant (20yrs, married, mother of two).

Another woman respondent narrated how her spouse was opposed to contraceptives and therefore did not want to listen to anything related to them:

Respondent: To me it was a surprise because I wasn't planning to get pregnant, I had planned to take care of the other 2 before I would think of getting another one. I came to the hospital and when I was tested they found that I was expecting when I went back home I told him though I was so shocked.

Interviewer: You told me that you cannot talk to him about family planning and tracking of menses, how did you tell him about this pregnancy?

Respondent: I told him that I want to go the antenatal clinic because I was expectant, for him he wants many children and he was happy about it. (25 years a married, mother of three).

Some couples experienced conflicts due to differences in preferences on contraceptive use. According to an experience shared by one of the study participants, some men had strongly opposed the use of contraceptives, sometimes causing family conflicts;

Respondent: It did not happen unexpectedly; I had gone for family planning injection then later on there were wrangles (conflicts) with my partner then I gave in and removed it, so it did not come unexpectedly (22 years, a married, mother of two).

Although there were programs that sought to include men in family planning practices, few men had participated in them in the area. Many women concurred that their part- ners had negative attitude towards contraceptives as they associated them with infertility, ailments, deformities, and preterm births.

\section{PERCEPTIONS ON THE EFFECTIVENESS OF CONTRACEPTION}

Although most women in the study confirmed that they were on some family planning method, some of them doubted the efficiency of the contraceptives. They perceived them to have some level of unreliability that allowed instances of unintended pregnancies. Below, two respondents explained how contraceptive failure led to accidental pregnancies:

Respondent: Baby (names withheld) happened unexpectedly, I was on the injectable family planning. I came for the injection in the $9^{\text {th }}$ month and I was due again in the 12 month for another injection, but the date was not due I became sick when I came to the hospital I was tested and found to be pregnant. (28years, married, mother of two).

Another participant narrates a similar experience of being on a contraceptive and expectant at the same time.
Respondent: Why am saying that I did not plan for it is because when I had my baby who is now 8 years, I used to go for the family planning injection for 3 months. During the time I was on injection, I could still get my menses and so I knew that even a week after my menses I could not conceive. Actually, I was on injection and expectant at the same time, that is what happened ( 25 years, married, mother of two).

Health workers interviewed perceived that the unintended pregnancies were among women using contraception and ART drugs. They felt that the use of ARTs interfered with the efficiency of some of the contraceptives occasionally resulting in unintended pregnancies.

\section{PERCEPTIONS ON THE IMPACT OF CONTRACEPTION ON BIRTH OUTCOMES}

It also emerged that some of the community members believed preterm births were related to the use of some contraceptives, especially long-term methods, as explained by one woman below:
Interviewer: What do you think causes a woman to have a preterm baby?
Respondent: Maybe if she used family planning meth- ods for many years
Interviewer: What type of family planning method?
Respondent: The five-year type.
Interviewer: [interruption] You were telling me that if a person uses the long term family planning methods she would get a preterm baby.
Respondent: Yes, if she uses them for many years (19 years, married, mother of two)

Another respondent described her fears of family planning leading to birth defects:

Respondent: I never knew I would conceive again, Interviewer: Why do you say that you never knew you 
can get pregnant again?

Respondent: After giving birth to my first daughter, I used the family planning method that takes 5 years, and people could give some horrifying experiences that the method makes some babies be born with deformities and that made me worried. I never knew I could get another baby because I was using family planning (21 years, married, mother).

\section{DISCUSSION}

The United Nations has prioritized family planning and contraceptive use in the Sustainable Development Goals (SDGs) as a key strategy of improving maternal-child health and ensuring sexual and reproductive health rights. ${ }^{2}$ Still, at least 14 million unintended pregnancies occur in sub-Saharan Africa most of which are linked to poor access and low uptake of contraceptives. ${ }^{8}$ Varied factors are associated with the unmet need for family planning and contraceptive services among both married and unmarried women in the developing world. Like in most of the other developing countries, the unmet need for contraception persists in Kenya despite an increase in awareness and availability of the services. Studies indicate that $53 \%$ of married and $61 \%$ of unmarried women use contraceptives in Kenya. ${ }^{6}$ Socioeconomic, demographic, and geographic disparities in contraceptive access and use remain wide with significant implications on the attainment of sexual and reproductive health rights. ${ }^{11}$ More women in urban areas access and use contraceptives compared to their counterparts in rural areas.

In this study, while the levels of knowledge about contraceptives were relatively high, the access and use of contraceptives remained low among some categories of people in the community. Overall, women continue to surpass their desired number of children despite a significant contraceptive awareness, accessibility and availability. For instance, adolescents had lower levels of knowledge as well as greater unmet need for contraceptives compared to other categories of sexually active people. Studies have documented similar findings in several SSA countries confirming lower contraceptives awareness and the highest prevalence of unintended and unwanted pregnancies among adolescents. ${ }^{12}$ This finding contradicts Kenya demographic health survey (2015) that established higher access to contraceptives among unmarried sexually active women compared to the married ones. ${ }^{6}$ However, it should be noted that our sample only consisted of women who already had children, even the adolescents, therefore, were limited to those who were most likely less knowledgeable than the average adolescent who was able to avoid a birth at that age. Studies confirm that most of the adolescents faced morbidity and mortality from unsafe abortion due to their low contraceptive knowledge and uptake. ${ }^{13}$

Many of the respondents identified side effects of using contraceptives, especially related to menstruation. It was found that the most common side effects among the participants included irregular patterns of menstruation, excessive bleeding, and sometimes discontinuation of the menses. This finding resonates with studies in other countries which acknowledged that contraceptives impact on menstruation pattern and intensity, besides other effects such as low libido, vaginal wetness, and decreased sexual pleasure among others. ${ }^{9}$ Although some of the side effects have been documented by other studies as myths and misconceptions, their impact on contraceptives uptake cannot be overemphasized. ${ }^{8}$ Some of the perceived and experienced side effects of contraceptives often led to a negative attitude and unwillingness to use contraception, or to discontinuation of these methods. Other studies have linked the perceptions of side effects to inadequate information on contraceptives, cultural constructs on reproductive behavior, and gender power dynamics. ${ }^{9}$ Respondents in the study also associated contraceptives with negative birth outcomes including deformities and preterm births. On the contrary, other studies have established contraceptive use as an important means of preventing adverse birth outcomes including preterm births. ${ }^{14}$ It is important to note that respondents in the study had a preterm birth so they might have been more likely to think about this specific outcome or be looking for an explanation for their experiences. This finding is in concurrence with a similar study in Uganda that established fear of adverse effects such as infertility and poor birth outcomes as some of the deterrents to the use of contraceptives. ${ }^{5}$ Women's education in the community was found to be instrumental in addressing some of the unfounded fears and misconceptions related to contraceptives. ${ }^{15}$ The developers of the hormonal injections and implants should also consider further research on how to address some of the widespread concerns such as effects on menstruation. This could significantly reduce the unmet need for contraceptives in rural communities in developing countries.

Although contraceptives generally received approval from most of the community members in the study, their efficiency was a concern. Some of the participants confirmed that the methods they were using had failed them and occasionally resulted in unintended pregnancies. A study conducted across Africa confirms that the efficacy of contraceptives in preventing unintended conceptions was not fully established as cases of failures have occasionally been documented. ${ }^{12}$ As revealed by further inquiry on the contraceptive failures in our study, several factors could be responsible for the failures, for instance, health status of the person using the contraceptive, drugs taken for other illnesses while on contraceptives, knowledge on fertility and contraceptives used among other factors.

While most people appreciated the use of contraceptives, different categories of people in the community had varied perspectives on the same. More men were averse to contraceptive use in their families sometimes, leading to conflicts with their partners who supported the use. These conflicts sometimes led to women discontinuing their methods or getting pregnant when they did not desire another pregnancy. This finding echoes others that have identified opposition from partners as a significant factor in low contraceptive uptake among married women. ${ }^{5}$ The impact of obstructive partners have been documented in studies in South Africa where male partners' demands for more children and also the gender power dynamics that sometimes contribute to discontinuation of contraceptive use in many families. ${ }^{9}$ Active involvement of men in family planning programs has 
been emphasized by policy-makers as a way of addressing spousal conflicts affecting uptake of contraceptives. ${ }^{3}$ The younger people were more aware of modern methods and largely supportive of contraceptives use while the elderly still preferred the traditional methods. Some studies have documented challenges of access to contraceptives among the younger generation as the main obstacle to meeting their contraceptives needs while for the older generation, the obstacle is in their beliefs and perspectives of contraceptives. ${ }^{15}$ Other literature cites cultural and social norms that emphasize traditional role of the woman as childbearing, prohibits contraceptive use, limits communication on reproductive health in the family and values large families. ${ }^{16}$ There is a need to create more awareness and education especially to men and other categories of people who view contraceptives negatively to improve uptake of these methods.

Even though contraceptives are mainly used for fertility control, some are important in preventing sexually transmitted infections. For instance, condoms are used both to prevent unwanted pregnancies and STIs. It was however noted that in the study, little attention was paid to STI prevention function of contraceptives as most of the respondents focused on the efficiency and side effects of contraceptives on fertility and health.

Like any other research, the study had some limitations. Since it focused on adolescent mothers and adult mothers and fathers, we missed the voices of male adolescents and women and men who had not given birth. Thus, these findings may not adequately represent the knowledge levels and perceptions of the community on contraceptives, menstruation, and preterm birth more broadly. The voices of adolescent boys may be especially important for future research, since they are sexually active and decision-makers about contraceptives. Additionally, the study was conducted in a rural set up in western Kenya, therefore it may not depict the general situation on contraceptive knowledge and perception across the country or anywhere else. Nonetheless, the study gives useful insight into contraceptive knowledge and experience of a rural setting in a developing country.

\section{CONCLUSIONS}

The study found that although most people had information on contraception, negative perceptions remained, potentially limiting use. Although a majority of women in the study believed that some contraceptives negatively affect- ed menstruation patterns, the role of contraceptives in the spacing of births and maternal health were largely appreciated. Therefore, it is necessary to strengthen their knowledge of contraceptives to maintain use and increase acceptance among those who are averse to the methods. Sociocultural factors influencing perceptions of contraceptives play a significant role in access and by extensions infant and maternal health outcomes in the community. Strengthening the link between the rural communities and the health facilities would play a major role in improving contraceptive knowledge, access, and use. Additionally, community education that target men and young people would significantly help in mitigating poor attitude and the low uptake of contraceptives, especially in rural areas.

Acknowledgements: We appreciate the ERC at Jaramogi Oginga Odinga Teaching and Referral Hospital, Kisumu that approved the study and Bondo Sub County Health Department that permitted us to use their health facilities at Uyawi, Got Agulu and Usigu. Many thanks to the Jaramogi Oginga Odinga University of Science and Technology for the support during the study.

Funding: The study was funded through Preterm Birth Initiative at the University of California, San Francisco under a larger grant from the Bill and Melinda Gates Foundation.

Authorship contributions: GO developed the concept and drafted the original manuscript. NDS and GA guided in the literature review and methodology. SA participated in proof reading and editing.

Competing interest: The authors completed the Unified Competing Interest Form at www.icmje.org/coi-diclosure.pdf (available upon request from the corresponding author), and declare no conflict of interest.

\section{Correspondence to:}

George Otieno Onyango Jaramogi Oginga Odinga University of Science and Technology

Bondo, Kenya

gotieno88@gmail.com 


\section{REFERENCES}

1. Durowade KA, Omokanye LO, Elegbede OE, et al. Barriers to contraceptive uptake among women of reproductive age in a semi-urban community of Ekiti State, Southwest Nigeria. Ethiop J Health Sci. 2017;27(2):121-128. doi:10.4314/ejhs.v27i2.4

2. Riley C, Garfinkel D, Thanel K, et al. Getting to FP2020: Harnessing the private sector to increase modern contraceptive access and choice in Ethiopia, Nigeria, and DRC. Dangal G, ed. PLoS ONE. 2018;13(2):e0192522. doi:10.1371/journal.pone.0192 $\underline{522}$

\section{African Population and Health Research Center.} What It Takes: Meeting Unmet Need for Family Planning in East Africa. Nairobi: African Population and Health Research Center; 2018.

4. Machiyama K, Casterline JB, Mumah JN, et al. Reasons for unmet need for family planning, with attention to the measurement of fertility preferences: Protocol for a multi-site cohort study. Reprod Health. 2017;14(1). doi:10.1186/s12978-016-0268-Z

5. Thummalachetty N, Mathur S, Mullinax M, DeCosta K, Nakyanjo N, Lutalo T, et al. Contraceptive Knowledge, Perceptions and Concerns among Men in Uganda. BMC Public Health. 2017;17(792).

6. Kenya National Bureau of Statistics and ICF International. Rockville, Maryland, USA: KNBS and ICF International; 2015.

7. Cates W Jr. Family planning: The essential link to achieving all eight Millennium Development Goals. Contraception. 2010;81(6):460-461. doi:10.1016/j.con traception.2010.01.002

8. Silumbwe A, Nkole T, Munakampe MN, et al. Community and health systems barriers and enablers to family planning and contraceptive services provision and use in Kabwe District, Zambia. BMC Health Serv Res. 2018;18(1):390. doi:10.1186/s1291 3-018-3136-4
9. Kriel Y, Milford C, Cordero J, et al. Male partner influence on family planning and contraceptive use: Perspectives from community members and healthcare providers in KwaZulu-Natal, South Africa. Reprod Health. 2019;16(1). doi:10.1186/s12978-019-0 $\underline{749-\mathrm{y}}$

10. Sedgh G, Ashford LS, Hussain R. Unmet Need for Contraceptives in Developing Countries: Examining Women's Reasons for Not Using a Method. New York: Guttmacher Institute; 2016.

11. Bellows B, Bulaya C, Inambwae S, Lissner CL, Ali M, Bajracharya A. Family Planning Vouchers in Low and Middle Income Countries: A Systematic Review. Studies in Family Planning. 2016;47(4):357-370. doi:1 $\underline{0.1111 / \text { sifp. } 12006}$

12. Iyanda AE, Dinkins BJ, Osayomi T, Adeusi TJ, Lu Y, Oppong JR. Fertility knowledge, contraceptive use and unintentional pregnancy in 29 African countries: A cross-sectional study. Int J Public Health. 2020;65(4):445-455. doi:10.1007/s00038-020-01356-9

13. Håkansson M, Super S, Oguttu M, Makenzius M. Social judgments on abortion and contraceptive use: A mixed methods study among secondary school teachers and student peer-counsellors in western Kenya. BMC Public Health. 2020;20(1):493. doi:10.11 86/s12889-020-08578-9

14. Muhihi A, Sudfeld CR, Smith ER, et al. Risk factors for small-for-gestational-age and preterm births among 19,269 Tanzanian newborns. BMC Pregnancy Childbirth. 2016;16(1):110. doi:10.1186/s12884-016-0 900-5

15. Asif MF, Pervaiz Z. Socio-demographic Determinants of Unmet Need for Family Planning among Married Women in Pakistan. BMC Public Health. 2019;19(1):1226. doi:10.1186/s12889-019-748 $\underline{7-5}$

16. Mejía-Guevara I, Cislaghi B, Weber A, et al. Association of collective attitudes and contraceptive practice in nine sub-Saharan African countries. Journal of Global Health. 2020;10(1). doi:10.7189/jog h.10.010705 